\title{
Simulasi Numerik pada Rectangular Cylinder dekat Dinding yang mengunakan Diffuser dan tanpa Diffuser dengan Mengunakan K $\varepsilon$ Model
}

\author{
Numerical Simulation On Near Wall Rectangular Cylinder Use \\ Diffuser And Without Diffuser Using K $\varepsilon$ Model
}

\author{
Nuzul Hidayat \\ Jurusan Teknik Otomotif Universitas Negeri Padang Email : nuzulhidayat1601 @ gmail.com
}

\begin{abstract}
Rectangular Cylinder with a rectangular cross section is also used as a building, the architectural features of the building, the internal flow geometry, and beam. In addition, flow around Rectangular Cylinder can produce local instability and can lead to global instability. Diffuser can work for both conditions by reducing the drag force and increase down force. Diffuser is designed to change the fluid kinetic energy into potential energy in the form of pressure. The increase in pressure that occurs in the diffuser will generate a positive pressure gradient or also called adverse pressure gradient (APG). In this case Rectangular Cylinder that use Diffuser And Without Diffuser at Re $1 \times 10^{6}$ obtained graphs of: (a) Drag Coefficient (Cd) (b) Lift Coefficient $(\mathrm{Cl})$ and (c) Velocity contour in the area of mid span numerically using the software Fluent 6.3 .26 with $\mathrm{k} \varepsilon$ - turbulence models that Standard are two-dimensional (2D). On the Cylinder Rectangular diffuser values obtained using 1:36 $\mathrm{Cd}$ and $\mathrm{Cl}-0.81$ and Rectangular Cylinder without diffuser obtained value $\mathrm{Cd} \mathrm{Cl} \mathrm{0:47} \mathrm{and} \mathrm{1:53,} \mathrm{clearly} \mathrm{visible}$ on the use Rectangular Cylinder diffuser turns diffuser provides greater $\mathrm{Cd}$ and $\mathrm{Cl}$ negative or increase down force. The treatment is to eliminate the other side upper corner on the front of a quarter circle with $r=0.1$, this produces a different contour velocity when compared experiment this treatment capable of eliminating reattached flow on the upper side area.
\end{abstract}

Keyword: Reattached flow, Rectangular Cylinder, Diffuser, Drag Coefficient (Cd), Lift Coefficient (Cf)

\section{PENDAHULUAN}

Masalah Rectangular Cylinder paling mendasar pada fluida dinamis seperti silinder melingkar dan persegi telah diteliti secara ekstensif baik secara numerik dan eksperimental. Pada struktur kendaraan seperti aliran di sekitar dekat dengan dinding pesawat memiliki

Subyek penelitian luas [1] penelitian secara numerik tentang efek dari ketinggian gap dari dasar pada medan aliran wake tidak stabil sekitar Rectangular Cylinder dekat dengan dinding.

Mereka menyimpulkan bahwa dengan memberikan potongan horizontal dan vertikal pada pelat hambatan pada bagian bawah dapat mengurangi vortex shedding dan mengurangi drag aerodinamis dan gaya angkat persegi panjang [2] mempelajari bangun persegi silinder ditempatkan dekat dinding pesawat di nilai yang berbeda dari hambatan untuk perbedaan tinggi dinding.
Hasil numerik mereka menunjukkan bahwa kekuatan dari vortisitas positif yang timbul dari sisi bawah hambatan berkurang ketika perbedaan ketinggian diturunkan. Pusaran shedding ditekan pada perbedaan ketinggian kritis. Koefisien rata-rata pada hambatan menurun dengan pengurangan ketinggian perbedaan gaya hambatan dan gaya angkat mengalami positif yang besar ketika dibawa dekat dengan dinding.

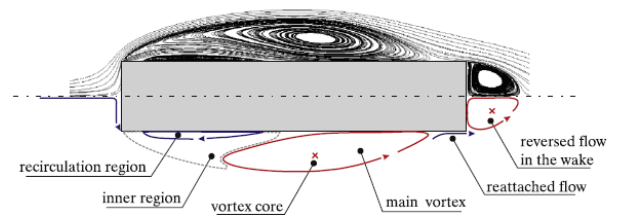

Gambar 1. Skema dari struktur aliran yang umumnya pada Rectangular Cylinder

Sedangkan diffuser adalah salah satu perangkat aerodinamis yang paling penting sering ditemukan pada Formula 1 [1]. Hal ini sering digunakan untuk mengurangi angkat untuk mobil balap. Dalam beberapa tahun terakhir, diffuser 
juga telah banyak digunakan dalam mobil biasa. Diffuser dapat bekerja untuk mengurangi drag dan meningkatkan downforce mengemudi mobil [3], yang dapat meningkatkan bahan bakar lebih ekonomis dan stabilitas dalam mengoperasi kendaraan [4]. Telah terbukti dalam penelitian yang diterbitkan oleh Cederlund dan Lasse Christoffersen, bahwa struktur bangun dari roda belakang dan sayap belakang untuk mobil sport dapat memiliki signifikan berpengaruh pada aliran udara melalui diffuser $[5,6]$.

Ini juga telah ditunjukkan dalam studi yang diterbitkan bahwa sudut diffuser dan ground clearance merupakan peran penting dalam fungsi diffuser [7].

Diffuser merupakan sebuah saluran tertutup dengan penampang melintang yang membesar sepanjang arah aliran. Diffuser didesain untuk merubah energi kinetik fluida menjadi energi potensial dalam bentuk tekanan. Peningkatan tekanan yang terjadi di dalam diffuser akan menghasilkan gradient tekanan yang positif atau disebut juga dengan adverse pressure gradient $(A P G)$. Adanya $A P G$ mengakibatkan perkembangan boundary layer yang sangat cepat dan semakin sensitif terhadap terjadinya separasi aliran di dalam diffuser.

Terjadinya separasi merupakan salah satu faktor yang mempengaruhi nilai coefficient pressure ( $C p)$ suatu diffuser. Hal tersebut mengakibatkan diffuser pressure recovery menjadi rendah apabila aliran di dalam diffuser mengalami separasi akibat $A P G$ yang sangat besar. Jika hal ini terjadi performa diffuser akan menurun.

Dalam penelitian ini peneliti mengunakan 2 objek penelitian yaitu pada Rectangular Cylinder dengan diffuser dan Rectangular Cylinder tanpa diffuser. Penelitian ini bertujuan untuk mengetahui karakteristik boundary layer turbulen pada Rectangular Cylinder yang mengunakan diffuser Dan tanpa diffuser untuk kasus $R e$ $1 \times 10^{6}$ dengan cara mendapatkan grafik bagaimana pengaruh pengunaan diffuser terhadap a) Drag Coefficient $(C d)$ (b) Lift Coefficient $(\mathrm{Cl})$ dan (c) Velocity contour
Parameter tersebut diukur pada daerah mid span dengan $R_{e}=1 \times 10^{6}$. Penelitian ini juga bertujuan untuk membandingkan hasil penelitian secara eksperimen dengan hasil penelitian secara numerik menggunakan software Fluent 6.3.26 dimana pada penelitian secara numerik digunakan turbulence model yaitu $k \varepsilon$ - Standar. Analisa pada penelitian numerik dilakukan secara 2 dimensi (2D).

\section{Formulasi Matematika}

Menggunakan Reynold Averaged Navier Stokes Equations Dari Massa Dan Momentum :

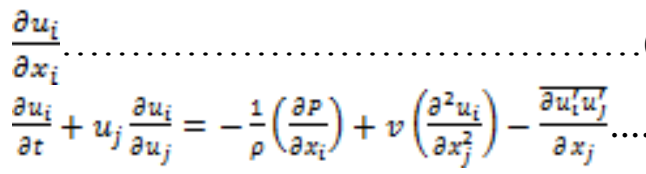

dimana $\mathrm{i}, \mathrm{j}=1,2$. Berikut $\mathrm{x}_{1}$ dan $\mathrm{x}_{2}$ menunjukkan arah horizontal dan vertikal, masing masing; $\mathrm{u}_{1}$ dan $\mathrm{u}_{2}$ adalah komponen kecepatan rata-rata; $\overline{u_{z}^{\prime} u_{j}^{\prime}}$ adalah komponen tegangan Reynolds dimana $u_{i}^{\prime}$ menunjukkan fluktuasi kecepatan; $\mathrm{P}$ adalah tekanan; dan $\rho$ adalah densitas dari fluida.

Tegangan Reynolds komponen, $\overline{u_{i}^{t} u_{j}^{t}}$ a, dinyatakan dalam viskositas turbulen $v_{T}$ dan aliran gradient rata-rata dengan menggunakan pendekatan Boussinesq,

$\overrightarrow{u_{1}^{\prime} u_{j}^{\prime}}=-v_{T}\left(\frac{\partial u_{f}}{\partial x_{f}}+\frac{\partial u_{f}}{\partial x_{i}}\right)-\frac{2}{a} k \delta_{i j}$

Di mana $\mathrm{k}$ adalah energi kinetik turbulen dan $\delta_{i j}$ adalah fungsi Kronecker. Sekarang para peneliti sering menggunakan standar bilangan Reynolds tinggi pemodelan k- $\varepsilon$ turbulensi. Model ini telah diterapkan Franke dan Rodi [9] untuk vortex shedding flow dengan. Persamaan $\mathrm{k}$ dan $\varepsilon$ ditunjukkan:

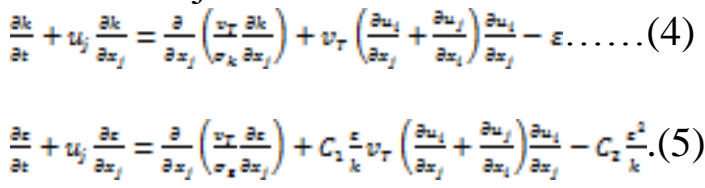

dimana $v_{T}=C \mu\left(k^{2} / \varepsilon\right)$ untuk koefisien standart

diambil dari 
$\left(C_{1}=1,44 ; C_{2}=1,92 ; C_{\mu}=\right.$

0,$09 ; \sigma_{k}=1,00 ; \sigma_{s}=1,3$ )

Prosedur Solusi Numerik, Domain Komputasi Dan Kondisi Batas

Reynolds-Averaged Navier Stokes

Equations untuk konservasi massa dan momentum, dalam hubungannya dengan standar bilangan Reynolds yang tinggi pada $\mathrm{K}-\varepsilon$ model, diselesaikan dengan menggunakan Metode First Order Upwind.

a. Aliran seragam dengan inlet $u_{1}=U_{\infty}$; $u_{2}=0$. Nilai inlet turbulensi aliran bebas

untuk energi kinetik $k=\left((3 / 2)\left(I_{u} U_{\infty}\right)^{2}\right)$ dan disipasi turbulen $\varepsilon=\left(\left(c_{\mu} k^{3 / 2}\right) /(0.1 L)\right)$ : hal ini telah disampaikan oleh Tutar dan Hold $\varnothing$ [10], hal ini telah dicoba pada intensitas turbulen $\left(I_{u}=\frac{u_{1}^{I}}{u_{\infty}}\right)$ adalah $1 \%$ dan panjang skala turbulen (L/D) adalah 0,01 .

b. Sepanjang batas keluar, $u_{1}, u_{2}$, k dan $\varepsilon$ ditetapkan sebagai kondisi batas bebas dalam konteks elemen terbatas. Ini berarti bahwa traksi tekanan kecepatan bebas, syarat batas diterapkan untuk $u_{1}, u_{2}$ dan $\mathrm{P}$, sedangkan fluks diatur sama dengan nol untuk $\mathrm{k}$ dan $\varepsilon$. Sepanjang batas atas dan bawah, $u_{1}, \mathrm{k}$ dan $\varepsilon$ adalah bebas, sedangkan $u_{2}$ ditetapkan sama dengan nol.

c. Permukaan Rectangular Cylinder noslip condition $u_{1},=u_{2}=0$

d. $k$ dan $\varepsilon$ dekat diding Rectangular Cylinder

$k=\frac{u_{*}^{2}}{\sqrt{C_{\mu}}}, \varepsilon=C_{\mu}^{3 / 4} \frac{k^{\mathrm{B} / 2}}{k h_{p}}$

untuk $\mathrm{k}=0,41$

\section{Model numerik}

Dalam model numerik ini peneliti harus sangat memperhatikan factor meshing untuk akurasi data. Pemberian meshing sangat diperhatikan pada daerah boundary layer yaitu pada bagian upstream setelah bluff body diamana grid dari meshing di rapatkan untuk mendapatkan yang valid. Dimensi yang digunakan adalah $33,6 \mathrm{~m} \mathrm{x}$ $8,88 \mathrm{~m}$, untuk gap $0.08 \mathrm{~m}$ dari dinding. Kemudian kecepatan aliran yang digunakan adalah $40 \mathrm{~m} / \mathrm{s}$. Sedangkan pada objek penelitian peneliti mengunakan 2 (dua) objek Rectangular Cylinder yaitu tanpa mengunakan diffuser dan dengan diffuser. Diffuser diberikan dengan cara memotong bagian belakang rectangular cylinder sebesar 0,2 ( lihat gambar 1)

a. Tanpa diffuser

Dengan skala $1: 0.1$ meter

$u_{1}=$ bebas $, \quad u_{2}=0, \quad k=$ bebas, $\varepsilon=$ bebas

$$
\begin{aligned}
& k=\frac{3}{2}\left(I_{u} U_{-}\right)^{z} \\
& \varepsilon=\frac{C_{u} k^{3 / 2}}{(0.1 L} \\
& u_{z}=0 \\
& u_{2}=U_{-}
\end{aligned}
$$

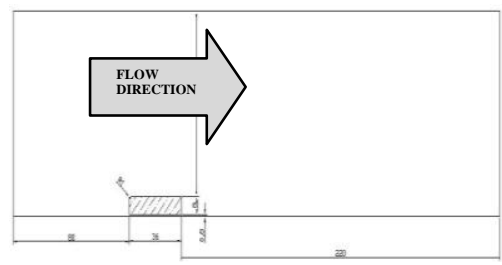

b. Dengan diffuser

$$
\begin{aligned}
& k=\frac{3}{2}\left(O_{u} U_{-}\right) \\
& \varepsilon=\frac{c_{\frac{1}{k}} k^{3 / z}}{(0,1 L} \\
& u_{z}=0 \\
& u_{2}=U_{-}
\end{aligned}
$$

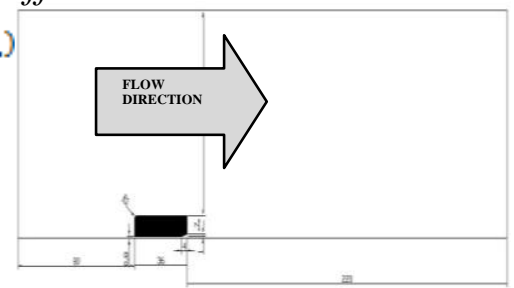

Jelas perbedaan terhadap benda uji dapat kita lihat dari gambar diatas dan juga boundary conditionnya

Rincian mesh Finite Elements yang digunakan dan Grid konvergensi. Dalam penelitian ini peneliti mengunakan 5 buah meshing diantaranya diberi kode $\mathrm{A}, \mathrm{B}, \mathrm{C}$, $\mathrm{D}$ dan $\mathrm{E}$ dengan masing node yang berbeda dari A sampai E dengan node yang semakin banyak. Untuk lebih jelasnya dapat dilihat pada table dibawah ini.

\section{a. Rectangular Cylinder Mengunakan Difusser}

Tabel 1. Perincian finite elements dan Grid konvergensi pada Rectangular Cylinder mengunakan difusser. 


\begin{tabular}{|c|c|c|c|c|}
\hline \multirow[t]{2}{*}{ Meshing } & \multicolumn{2}{|c|}{$\begin{array}{l}\text { Rectangular cylinder } \\
\text { dengan diffuser }\end{array}$} & \multirow[t]{2}{*}{ Nodes } & \multirow{2}{*}{$\begin{array}{l}\text { Finite } \\
\text { elements }\end{array}$} \\
\hline & $\mathrm{Cd}$ & $\mathrm{Cl}$ & & \\
\hline $\mathrm{A}$ & 0.719230 & -0.57320 & 16.144 & 15.812 \\
\hline $\mathrm{B}$ & 0.663715 & -0.52864 & 23.236 & 22.812 \\
\hline $\mathrm{C}$ & 0.562187 & -0.69620 & 54.536 & 53.580 \\
\hline D & 0.515943 & -0.81657 & 58.534 & 57.714 \\
\hline$E$ & 0.515164 & -0.81686 & 75.898 & 74.920 \\
\hline
\end{tabular}

Dari tabel diatas maka pada meshing

D dan E sudah medapatkan konvergensi dengan tingkat kesalahan 0.0779 untuk $\mathrm{Cd}$ dan 0.029 untuk $\mathrm{Cl}$ pada $R_{e}=1 \times 10^{6}$ maka untuk itu digunakan meshing D dengan bnayak nodes 59.235. dalam hal ini digunakan yang sedikit nodes agar dalan iterasinya lebih mudah mencapai konvergen.hal dapat dilihat pada grafik berikut

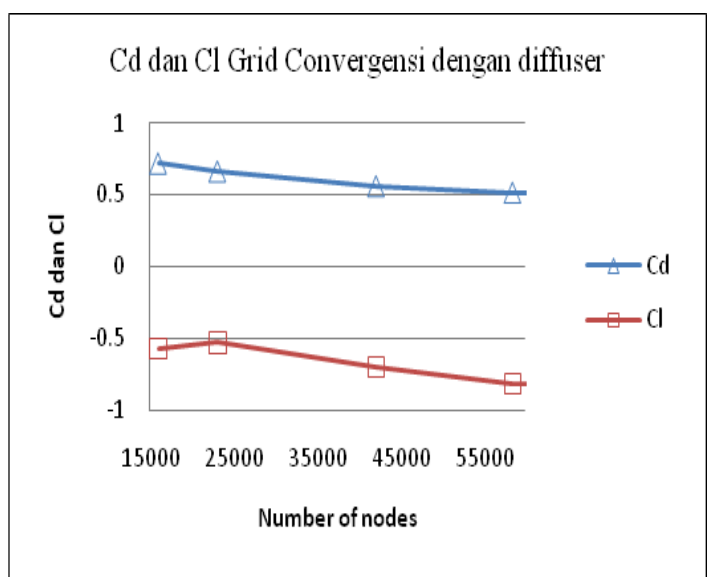

Grafik 1. Perincian finite elements dan Grid konvergensi pada Rectangular Cylinder mengunakan difusser pada $R_{e}=1 \times 10^{6}$

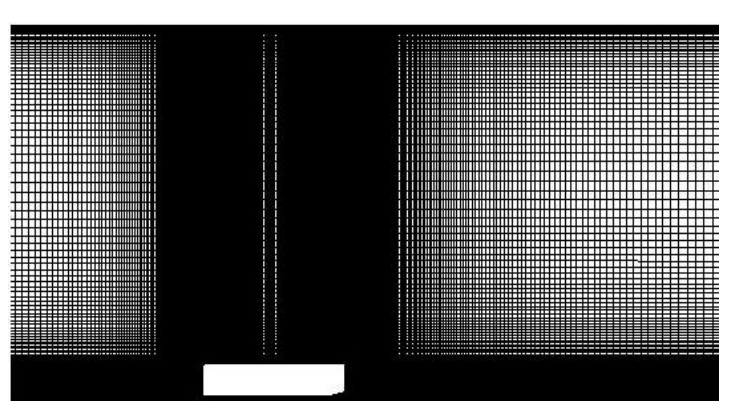

Gambar 2. Meshing $D 58.534$ nodes dan 57.714 finite elements dari Rectangular Cylinder mengunakan diffuser

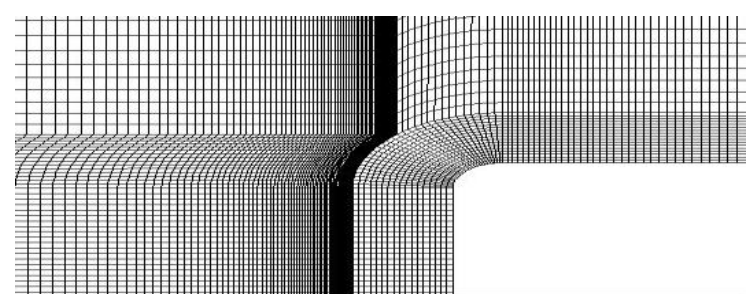

Gambar 3. Meshing $D$ dari Rectangular Cylinder mengunakan diffuser

b. Rectangular Cylinder Mengunakan tanpa Difusser

Tabel 2. Perincian finite elements dan Grid konvergensi pada Rectangular Cylinder tanpa difusser.

\begin{tabular}{|l|l|l|l|l|}
\hline \multirow{2}{*}{$\begin{array}{l}\text { Mes } \\
\text { hing }\end{array}$} & \multicolumn{2}{|l|}{$\begin{array}{l}\text { Rectangular cylinder } \\
\text { dengan diffuser }\end{array}$} & \multirow{2}{*}{ Nodes } & $\begin{array}{l}\text { finite } \\
\text { elemen } \\
\text { ts }\end{array}$ \\
\cline { 2 - 3 } & $\mathrm{Cd}$ & $\mathrm{Cl}$ & & 16.012 \\
\hline $\mathrm{A}$ & 0.738152 & 1.651223 & 16.340 & 16.238 \\
\hline $\mathrm{B}$ & 0.639192 & 1.624155 & 23.658 & 23.228 \\
\hline $\mathrm{C}$ & 0.512050 & 1.542121 & 46.143 & 45.468 \\
\hline $\mathrm{D}$ & 0.474517 & 1.532148 & 59.235 & 58.418 \\
\hline $\mathrm{E}$ & 0.474861 & 1.532899 & 82.773 & 81.800 \\
\hline
\end{tabular}

Dari tabel diatas maka pada meshing D dan E sudah medapatkan konvergensi dengan tingkat kesalahan 0.0344 untuk $\mathrm{Cd}$ dan 0.0759 untuk $\mathrm{Cl}$ pada $R_{e}=1 \times 10^{6}$ maka untuk itu digunakan meshing D dengan bnayak nodes 59.235. dalam hal ini digunakan yang sedikit nodes agar dalam iterasinya lebih mudah mencapai konvergen. Hal dapat dilihat pada grafik berikut:

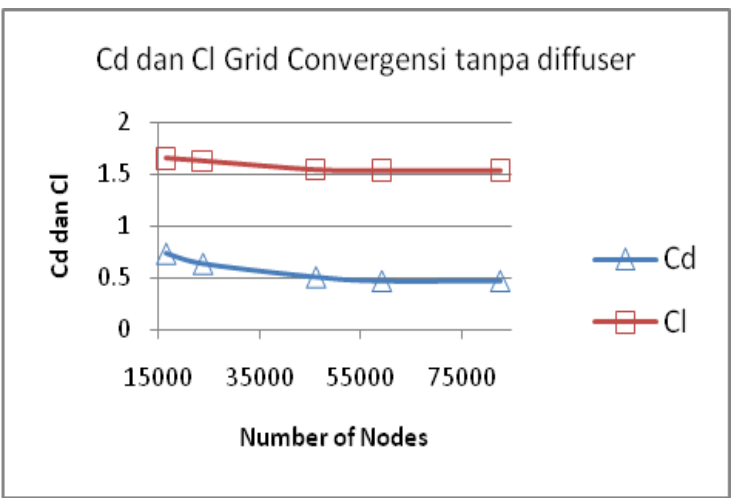

Grafik 2. Perincian finite elements dan Grid konvergensi pada Rectangular Cylinder mengunakan difusser pada $R_{e}=1 \times 10^{6}$ 


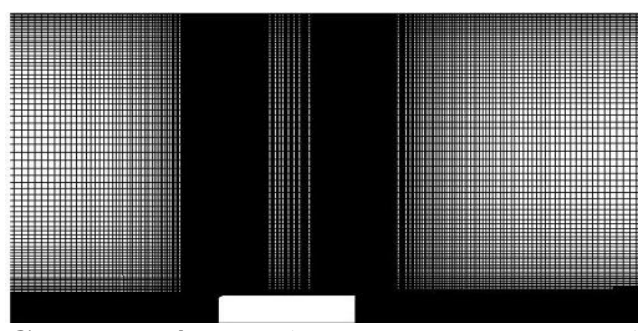

Gambar 4. Meshing $D 59.235$ nodes dan 58.418 finite elements dari Rectangular Cylinder tanpa diffuser

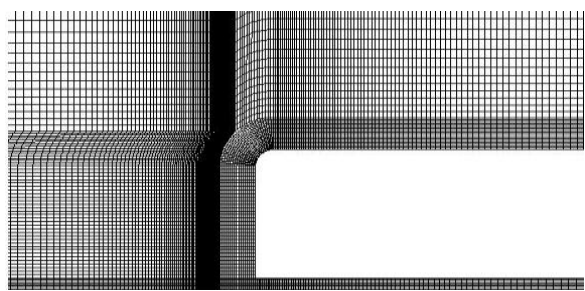

Gambar 5. Meshing $D$ dari Rectangular Cylinder tanpa diffuser

\section{HASIL DAN PEMBAHASAN}

Dari hasil komputasi $R_{e}=1 \times 10^{6}$ dan velocity $40 \mathrm{~m} / \mathrm{s}$ maka didapat data dengan mengunakan metode $\mathrm{K}-\varepsilon$ model. Data yang akan dianalisa adalah tentang perbandingan antara eksperiment dan pendekatan numeric terhadap koefisien drag, koefisien lift dan skin frictions, serta perbandingan turbulen intensitas pada pendekatan numerik yang mengunakan Rectangular Cylinder dengan diffuser dan tanpa diffuser.

\section{Koefisien drag $(C f)$ dan Koefisien Lift (Cf)}

Dalam hal ini peneliti membandingkan koefisien drag antara Rectangular Cylinder mengunakan diffuser dan tanpa diffuser

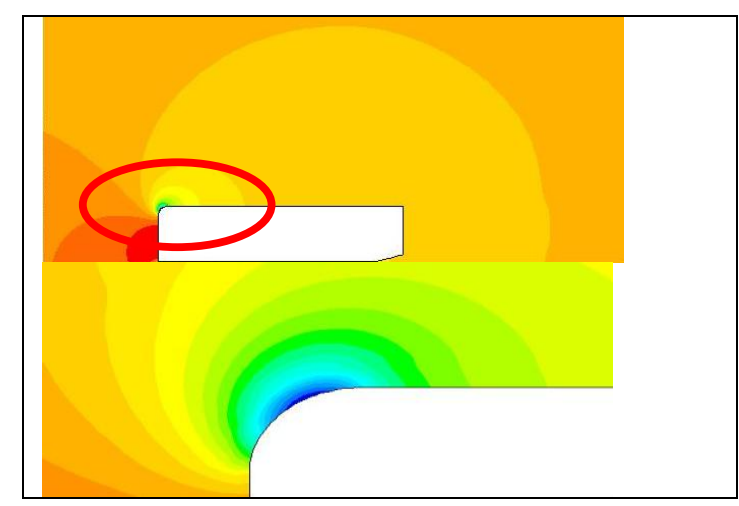

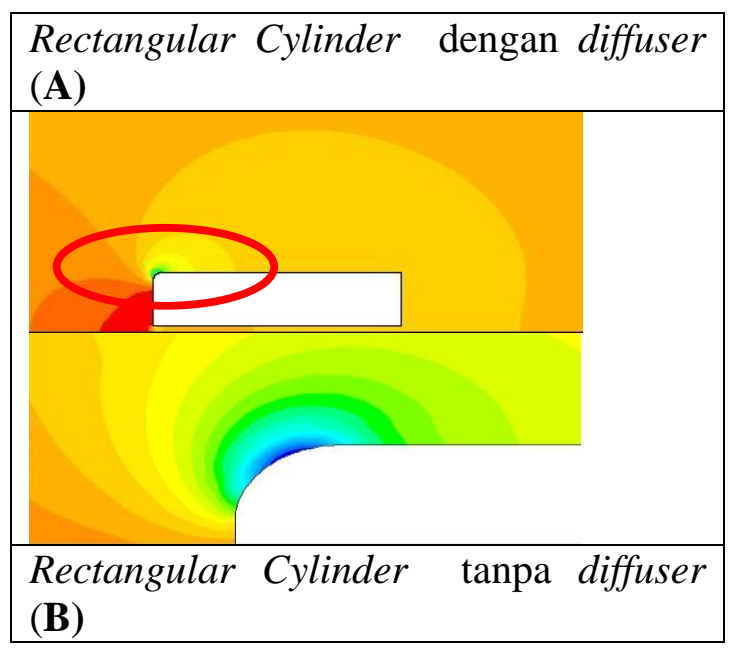

Gambar 6. Perbandingan Koefisien drag pada Rectangular Cylinder mengunakan diffuser dan tanpa diffuser

Dari gambar diatas (6A) pada bagian yang dilingkari dapat dijelaskan bahwa pada Rectangular Cylinder mengunakan diffuser koefisien drag pada daerah stagnasi lebih cendrung tinggi yaitu 1.3583443 dan tanpa diffuser 0.4737141 apabila kita bandingkan maka akan terlihat bahwa pada Rectangular Cylinder mengunakan diffuser Cd lebih besar dibandingkan tanpa diffuser ini diakibatkan oleh tekanan pada daerah stagnasi naik akibat aliran pada gap yang mengunakan diffuser lebih tinggi apabila dibandingkan tanpa diffuser. Dari aliran yang melalui gap lebih cepat terlepas atau dengan kata lain aliran yang terdapat pada gap tekanannya lebih rendah dibandingkan dengan Rectangular Cylinder tanpa diffuser karena daerah gapnya 0.4 lebih pendek. Sedangkan pada puncak dari Rectangular Cylinder dengan menghilangkan sudut siku kemudian diganti dengan $1 / 4$ lingkaran dengan diameter $0.1 \mathrm{~m}$ mengakibatkan koefisien pressure paling rendah didaerah tersebut. Yang seharusnya pada daerah tersebut adalah daerah yang memiliki koefisien pressure yang tinggi. Dengan memberikan sedikit modifikasi seperti ini ternyata dapat mengubah secara drastis koefisien drag apa bila dibandingkan dengan hasil experiment[8]. Hal ini sama apabila dibandingkan dengan Rectangular Cylinder tanpa diffuser. 
Kemudian pada gambar (6B) pada bagian yang dilingkari kita lihat koefisien drag pada daerah stagnasi lebih besar ini dibuktikan dengan warna gambar jauh lebih besar dibandingkan dengan diffuser ini dipengaruhi oleh gap yang panjang 0.4 dibandingkan dengan mengunakan diffuser hal ini membuat tekanan pada gap naik, semakin panjang area gap sempit maka tekanan pada area stagnasi akan semakin tinggi. Dalam hal ini memang pemberian diffuser pada Rectangular Cylinder dapat menaikan koefisien drag.

Jika kita analisa dari grafik koefisien pressure terhadap panjang Rectangular Cylinder

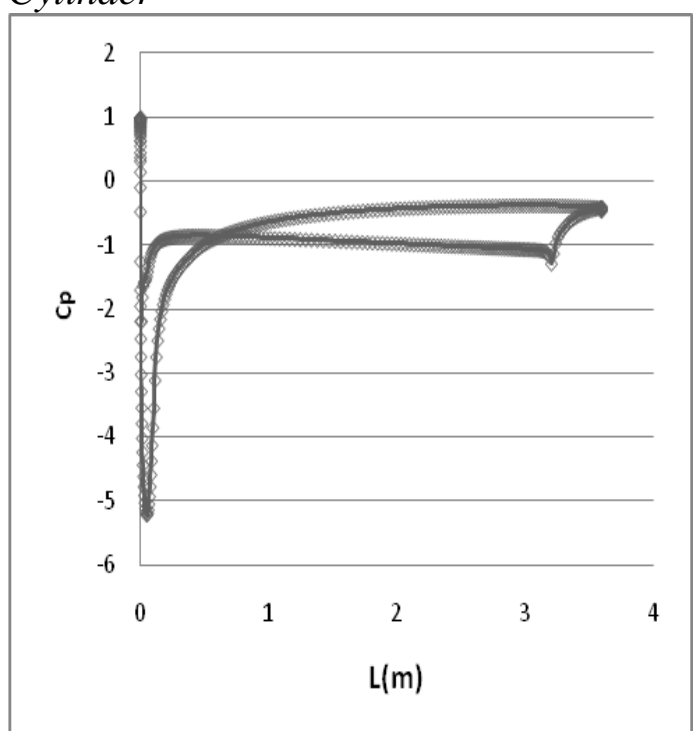

Grafik 3. Koefisien pressure pada Rectangular Cylinder mengunakan difusser pada $R_{e}=1 \times 10^{6}$

Dari grafik 3 diatas dapat dianalisa bahwa tekanan pada bagian lower side dari Rectangular Cylinder mengunakan difusser lebih cenderung lebih rendah dengan tekanan pada bagian upper side dari Rectangular Cylinder dan pada bagian lower lebih konstan sepanjang gap. Kemudian pada $\mathrm{L}=3.25 \mathrm{~m}$ terjadi penurunan tekanan yang diakibatkan diffuser pada $\mathrm{L}=3.25 \mathrm{~m}$ sekitar $\mathrm{Cp}=-1.1$ penurunan terjadi sepanjang diffuser atau $\mathrm{L}=3.6 \mathrm{~m}$ selanjutnya sampai ujung dari Rectangular Cylinder. Dan pada bagian kepala dari Rectangular Cylinder bagian depan mengalami koefisien pressure paling rendah yaitu pada jarak sekitar $\mathrm{L}=0.1 \mathrm{~m}$ dengan koefisien pressurenya $\mathrm{Cp}=-5.5 \mathrm{dan}$ kemudian naik sesuai countor Rectangular Cylinder menuju titik stagnasi, pada titik stagnasi mengalami tekanan yang paling tinggi pada $\mathrm{L}=0 \mathrm{~m}$ yaitu $\mathrm{Cp} 1$, kemudian setelah dari titik stagnasi kembali turun menuju gap pada $\mathrm{L}=0.1$ koefisien pressurenya $\mathrm{Cp}=-1$ dan cenderung konstan menuju belakang dari Rectangular Cylinder.

Pada Rectangular Cylinder mengunakan difusser koefisien pressure terdistribusi sepanjang gap akibat terjadinya tekanan yang cukup rendah, hal ini mengakibatkan tekanan pada upper side lebih besar sekitar $\mathrm{Cp}=0.5$ dibanding dengan lower side. Hal ini jelas terlihat pada $\mathrm{L}=3.25 \mathrm{~m}$ antara upper side dan lower side memiliki selisih $\mathrm{C} \mathrm{p}=1$ akibatnya terjadi nilai koefisien Lift $(\mathrm{Cl})$ bernilai negatife ini dibuktikan dengan hasil numeric yaitu untuk koefisien Lift $(\mathrm{Cl})=$ 0.81657 inilah alasan kenapa gaya angkat atau koefisien Lift (Cf) pada Rectangular Cylinder mengunakan difusser negatif.

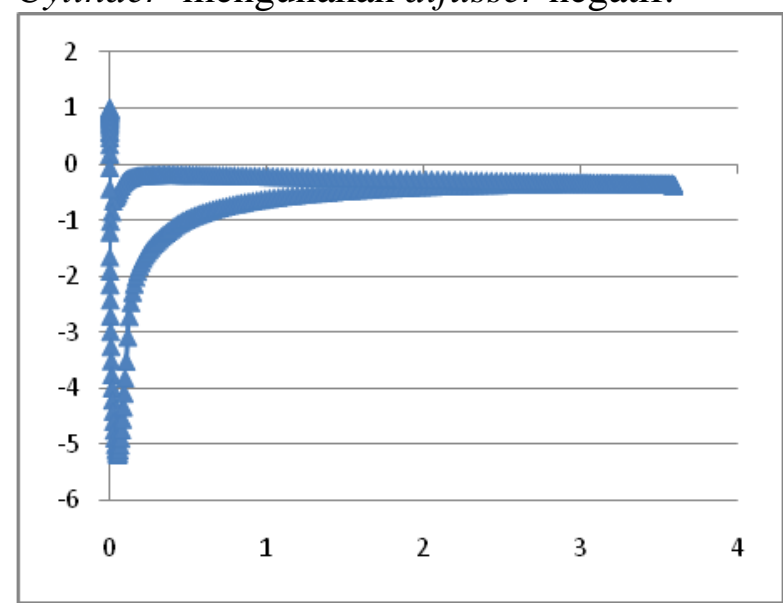

Grafik 4. Koefisien pressure pada Rectangular Cylinder tanpa difusser pada $R_{e}=1 \times 10^{6}$

Pada grafik 4 diatas maka dapat dianalisa bahwa koefisien pressure pada Rectangular Cylinder tanpa difusser pada bagian lower side cenderung lebih rendah dibanding bagian upper side ini dapat dilihat dan dan pada $\mathrm{L}=3$ maka $\mathrm{Cp}$ konstan baik upper side ataupun lower side. Kemudian kita lihat distribusi koefisien pressurenya pada daerah stagnasi $\mathrm{L}=0$ nilai $\mathrm{Cp}=1$ ini adalah tekanan yang paling 
tinggi, jika dibanding dengan Rectangular Cylinder dengan difusser ini lebih rendah, namun hal ini malah membuat distribusi sepanjang gap menjadi konstan akibatnya tekanan pada lower side lebih tinggi dari pada upper side. Kemudian tekanan turun sesuai counturnya dan yaitu pada $\mathrm{L}=0.1 \mathrm{~m}$ nilai $\mathrm{Cp}=-5.5$ hal ini jika dibandingkan dengan Rectangular Cylinder dengan difusser sama. Kemudian tekanan naik sesuai dengan counturnya dan seterusnya cenderung konstan sampai $\mathrm{L}=3.6$ atau ujung Rectangular Cylinder. Akibat dari distribusi tekanan pada upper side dan lower side di Rectangular Cylinder tanpa difusser menjadikan koefisien Lift $(\mathrm{Cl})$ pada Rectangular Cylinder tanpa difusser menjadi positif ini terbukti dengan pendekatan numerikal koefisien Lift $(\mathrm{Cl})=1.532148$

\section{Velocity Contour}

Setelah melakukan pendekatan secara numerik bahwa didapat data visualisasi bagaimana Velocity Contour yang terjadi pada Rectangular Cylinder dengan difusser dan Rectangular Cylinder tanpa difusser apakah dengan memberikan perubahan yang signifikan pada Rectangular Cylinder tersebut

Untuk lebih jelasnya dapat kita lihat pada gambar 7 .

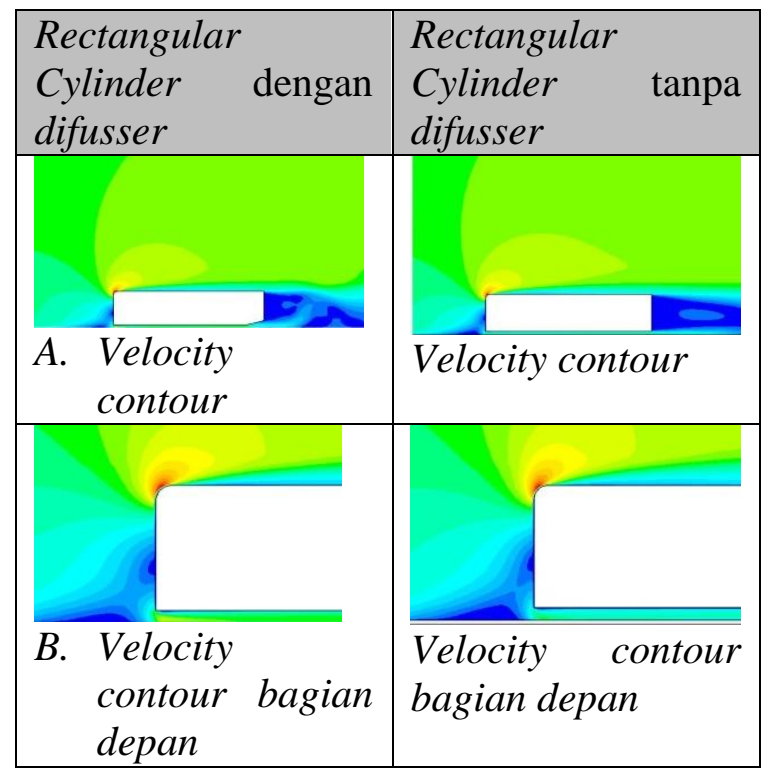
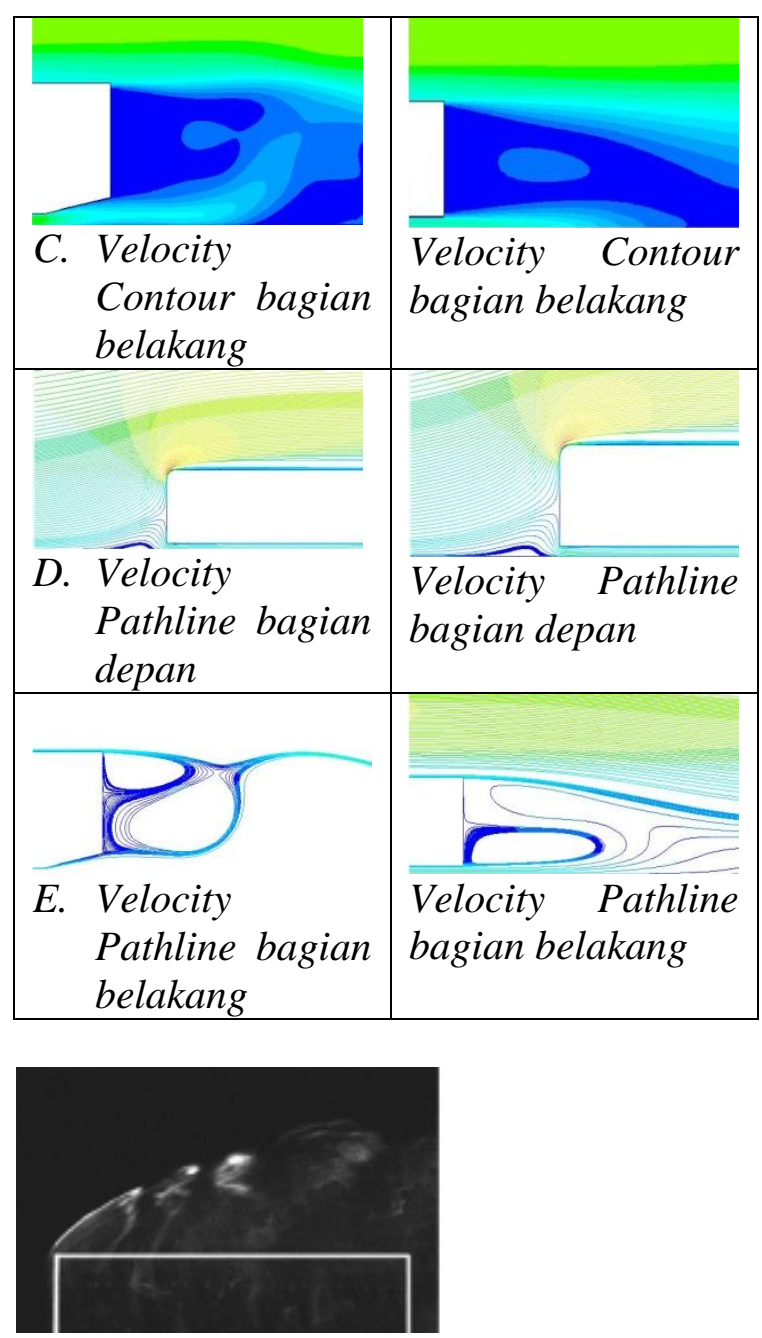

Gambar 8. Eksperiment [8] pada $R e_{D} 10$ 000: L/D 0.67

Dari gambar perbandingan diatas maka dapat kita analisa bahwa:

a. Pada gambar 7(A) bahwa perbandingan secara keseluruhan pada dengan Rectangular Cylinder dengan difusser dan Rectangular Cylinder tanpa difusser terhadap Velocity Contournya sangat jauh berbeda, pertama kita bandingkan dengan hasli eksperimen [5] bahwa dengan memodifikasi bagian sudut depan dari upper side dengan menghilangkan sudut $90^{\circ}$ ternyata dapat mengubah bentuk Velocity Contour secara signifikan yaitunya dapat menghilangkan terjadinya recirculation region yang nantinya akan membentuk vortex core dan selanjtnya menjadi main vortex dan jika Rectangular Cylinder panjang maka akan memungkinkan terjadinya 
reattached flow pada upper side atau lower side pada Rectangular Cylinder.

b. Pada gambar 7 (B) pada bagian dari depan Rectangular Cylinder dengan difusser terjadi separation bubble yang lebih kecil dibandingkan dengan Rectangular Cylinder tanpa difusser karena hal ini diakibatkan oleh tekanan yang dihasilkan oleh gap. Pada dengan Rectangular Cylinder dengan difusser tekananya rendah karena dengan adanya diffuser membantu mempercepat aliran yang terjadi pada gap maka separation bubble terjadi kecil kecepatan cenderung lebih tinggi dan pada Rectangular Cylinder tanpa difusser tekanan pada gap tinggi karena jarak tempuh aliran pada gap panjang karena sesuai dengan karakteristik fluida tidak suka dengan celah sempit, akibatnya separation bubble yang terjadi pada bagian depan lebih besar karena lairan lebih lambat. Kemudian untuk bagia depan pada titik stagnasi hamper sama dimana aliran dalam kecepatan 0. Dan aliran tertinggi terjadi pada sudut bagian upper side depan.

c. Pada gambar 7 (C) Velocity Contour setelah melewati Rectangular Cylinder, pada Rectangular Cylinder dengan difusser dapat dianalisa bahwa reversed flow in the wake lebih kecil atau adverse pressure lebih cepat terlepas karena aliran yang cukup tinggi ditimbulkan oleh diffuser mampu mendorong reversed flow in the wake disini terjadilah pelepasan vortex, dengan cepat terlepasnya vortex maka tingkat instability pada bagian belakang Rectangular Cylinder menjadi rendah artinya jika Rectangular Cylinder diluncurkan pada kecepatan aliran tinggi maka reversed flow in the wake tidak terlalu mempengaruhi vibration terhadap Rectangular Cylinder itu sendiri. Maka dari itu karena wake cepat terlepas tekanan sesudah difusser rendah akibatnya gaya lift $(c f)$ yang dihasilkan negatife, tekanan pada upper side lebih besar disbanding lower side.
Sedanglan pada Rectangular Cylinder tanpa difusser malah sebaliknya yaitu akibat aliran sepanjang gap mengalit pada tekanan yang cukup tinggi maka Velocity menjadi rendah, ini berdampak pada reversed flow in the wake ,karena kecepatan aliran setelah gap rendah maka tidak mampu untuk mendorong vortex yang terjadi akibat reversed flow in the wake akibatnya adverse pressure lebih lama terlepas ini ternyata mengakibatkan instability pada belakang Rectangular Cylinder tinggi akibatnya jika Rectangular Cylinder diluncurkan pada kecepatan aliran yang tinggi maka reversed flow in the wake akan mempengaruhi vibration menjadi besar. Rectangular Cylinder akan terangkat-angkat. Hal ini dapat kita buktikan dengan pendekatan numerik diatas bahwa hasil koefisien gaya lift (cf) positif.

d. Pada gambar 7 (D) dan (E) adalah Velocity Pathline untuk memperjelas bagaimana bentuk aliran disekitar Rectangular Cylinder dengan difusser dan Rectangular Cylinder tanpa difusser. Digambar dapat kita lihat bagaimana separation bubble dibagian depan Rectangular Cylinder dengan difusser lebih kecil dibandingkan separation bubble pada bagian depannya Rectangular Cylinder tanpa difusser, karena tekanan pada gap Rectangular Cylinder dengan difusser lebih rendah dengan adanya diffuser dan pada Rectangular Cylinder tanpa difusser tekanan pada gapnya lebih tinggi mengakibatkan blockage effect yang lebih besar.

Selanjutnya vortex pada bagian belakang Rectangular Cylinder dengan difusser lebih cepat lepas dibandingkan vortex pada Rectangular Cylinder tanpa difusser karena yang mengunakan diffuser kecepatan aliranyang keluar dari gap tinggi sehingga mendesak vortex untuk lepas dari belakang Rectangular Cylinder dan sebaliknya pada Rectangular Cylinder tanpa difusser kecepatan aliran keluar dari 
gap rendah sehingga tidak mampu vortex untuk lepas dari Rectangular Cylinder. Dari analisa diatas bahwa Velocity Contour pada sebuah Rectangular Cylinder sangat tergantung dari counturnya.

\section{SIMPULAN}

Setelah melakukan pendekatan secara numerik dan setelah menganalisa data dapat diambil beberapa kesimpulan:

1. Pada Rectangular Cylinder tanpa diffuser memberikan nilai $\mathrm{Cd}$ yang besar serta nilai $\mathrm{Cl}$ yang positif, dan pada Velocity Contour juga mengakibatkan adverse pressure yang dihasilkan oleh reversed flow in the wake lambat untuk terlepas dari bagian belakang Rectangular Cylinder ini mengakibatkan instability yang tinggi. Kemudian kecendrungan nilai $\mathrm{Cl}$ naik dengan naiknya Re. Ini memberikan dampak negative jika di aplikasikan pada kendaraan berkecepatan tinggi karena Rectangular Cylinder tidak mampu menahan vibrasi yang dihasilkan oleh adverse pressure .

2. Pada Rectangular Cylinder dengan diffuser terbukti sesuai dengan penelitian yang terdahulu bahwa dengan menambahkan diffuser pada bagian belakang Rectangular Cylinder agar mendapatkan $\mathrm{Cd}$ yang kecil dan nilai $\mathrm{Cl}$ negative atau downforce nya meningkat[11].

3. Dalam hal ini dapat diketahui bahwa kinerja dari diffuser adalah kebalikan dari air foil yang mana $\mathrm{Cl}$ yang diahasilkan berlawanan pada air foil bernilai positif dan pada diffuser bernilai negatif namun sama-sama memiliki kesamaan yaitu mengurangi Cd. Dalam hal ini hanya bermain pada kecepatan dan tekanan yang terjadi pada upper side dan lower side.Pada diffuser kecepatan aliran pada upper side lebih rendah dibandingkan dengan lower side akibatnya distribusi tekanan pada bagian upper side lebih besar dari pada lower side akibatnya $\mathrm{Cl}$ negative sebaliknya pada air foil kecepatan pada bagian upper side lebih tinggi daripada lower side akibatnya distribusi tekanan pada upper side lebih rendah daripada lower side akibatnya nilai $\mathrm{Cl}$ positif.

\section{DAFTAR PUSTAKA}

[1] Lee B, Kim T, Lee D. Control of vortex shedding behind a rectangular cylinder near the ground. Numer Heat Transfer A 2005;47:787_804.

[2] Bhattacharyya S, Maiti DK. Shear flow past a square cylinder near a wall. Inter J Eng Sci 2004;42:2119_34.

[3] J. P. Howell. The Influence of Ground Simulation on the Aerodynamic of Simple Car Shapes with an Underfloor Diffuser, Conference on Vehicle Aerodynamics. Royal Aerodynamic Society, 1994

[3] Kevin R. Cooper, T.bertenyi, G. Dutil,J. syms, G. Sovran. The Aerodynamics Performance of Automobile Underbody Diffuser. SAE Technical Paper 980030, 1998

[4] Ye Hui. A Parametric Study on the Diffuser and Ground Clearance of a Simplified Car Model using CFD. Jilin university, 2006

[5] Cederlund, J. and Vikström, J. The Aerodynamic Influence of Rim Design on a Sports Car and its Interaction with the Wing and Diffuser Flow. M.Sc. Thesis, Chalmers University of Technology, 2010

[6] Lasse Christoffersen, David Söderblom, Lennart Lofdahl. Wing-Diffuser Interaction on a Sports Car. SAE Technical Paper 2011-01-1433, 2011

[7] Fu Limin. Automobile Aerodynamics. Beijing: China Machinery Press, 2006 
[8] H. Higuchi, P. van Langen, H. Sawada, C.E. Tinney. Axial flow over a blunt circular cylinder with and without shear layer reattachment. Syracuse University, 2006

[9] Franke R, Rodi W, Scho“nung B. Analysis of experimental vortex shedding data with respect to turbulence modeling. In: Proceedings of the 7th turbulent shear flow symposium; 1989. p. 24.4.1-24.4.5. Stanford, USA.

[10] Tutar M, Holdo AE. Computational modeling of flow around a circular cylinder in sub-critical flow regime with various turbulence models. Int $\mathrm{J}$ Numer Meth Fluids 2001;35:763-84.

[11] Xingjun. et al. Influence of Different Diffuser Angle on Sedan's Aerodynamic Characteristics. State Key Laboratory of Automobile Simulation and Control, Jilin University, Changchun2011 